\section{\#YardFruits: Twitter as a Tool to Disseminate Horticulture Education during a Pandemic}

\author{
Eric T. Stafne ${ }^{1}$
}

AdDitionAl INDEX wORDs. analytics, engagement, extension, hashtag, social media

Summary. Since late Mar. 2020, many universities halted normal operations due to the Coronavirus Disease 2019 (COVID-19) pandemic. Although extension uses many different techniques to educate consumers, it has been slow to grasp the power of social media. Faced with a dilemma of using digital methods instead of in-person field days, short courses, and workshops, Twitter was a viable alternative, especially for broad audience engagement. Tweet threads were posted on Twitter every Monday morning from 6 Apr. to 8 June 2020. Each thread consisted of 10 tweets. A hashtag \#YardFruits was used to start the thread and for later reference. For the first nine threads only one fruit species was discussed per thread. The final thread consisted of single tweets of several species. Engagement percentage did not differ over time but did differ among the crop species. Tweets that did not include a photo received less engagement $(2.7 \%)$ than those that did include a photo $(4.7 \%)$. My Twitter account saw a $6.5 \%$ increase in followers during the series. Grape (Vitis sp.), passion fruit (Passiflora sp.), fig (Ficus carica), and pear (Pyrus communis) threads had the least engagement and were different from the Other Fruits thread. All other threads were similar. Extension educators can grow their influence by using welltargeted, focused tweets and tweet threads, especially those that use hashtags and photos.

S ince late Mar. 2020, many universities halted normal operations due to the COVID-19 pandemic, forcing faculty and other educators to use new, digital methods of educational delivery. Although extension uses many different techniques to educate consumers, it has been slow to grasp the power of social media (Barton et al., 2017). Although powerful, the educational experience using these platforms has limitations and certain guidelines are needed to improve outcomes (Su et al., 2017; Zhang et al., 2020). Remote delivery via webinars has proven successful (Hoke et al., 2018; Particka et al., 2018) but social media platforms can potentially reach more consumers. Twitter (Twitter, Inc., San Francisco, CA) is one such tool and it has been successfully used during times of crisis, such as extreme drought (Wagler and Cannon, 2015) and hurricanes (Ruth et al., 2020).

Received for publication 21 Aug. 2020. Accepted for publication 16 Sept. 2020.

Published online 14 October 2020

${ }^{1}$ Coastal Research and Extension Center, Mississippi State University, Poplarville, MS 39470

E.T.S. is the corresponding author. E-mail: estafne@ ext.msstate.edu.

This is an open access article distributed under the $\mathrm{CC}$ BY-NC-ND license (https://creativecommons.org/ licenses/by-nc-nd/4.0/).

https://doi.org/10.21273/HORTTECH04717-20 digital methods instead of in-person education due to the COVID-19 pandemic, Twitter is a potential alternative. Fields outside of horticulture have used Twitter to educate and promote information (Chung, 2017; Su et al., 2017), as well as agriculture (Barton et al., 2017; Mills et al., 2019). The horticulture industry has been especially impacted by the pandemic with substantial crop losses due to lack of labor and transportation (Hummer, 2020). The spring months of 2020 were isolating for many while the initial wave of infections surged. Horticultural research was disrupted (Hummer, 2020), as well as extension and teaching activities. Whereas teaching pivoted toward online-only delivery during the spring semester and research was minimized to essential activities, there was prime opportunity for extension to reach a captive audience that was seeking interaction.

Therefore, the goal of this project was to use Twitter as a viable way to disseminate fruit-related horticulture information in lieu of face-to-face meetings and measure engagement metrics that could lead to assessment of knowledge gain or other impact.

\section{Materials and methods}

Tweet threads were posted on Twitter via my handle (@EStafne) every
Faced with a dilemma of using
Monday morning from 6 Apr. to 8 June 2020. Each thread consisted of 10 tweets that included information as well as a photo in most of them (Supplemental Fig. 1). All threads were first composed in Microsoft Word (Microsoft Corp., Redmond, WA), then edited to fit the 280-character limit of Twitter.

The thread was retweeted on Tuesday morning and Wednesday morning when it was archived on my blog site (Stafne, 2020). A hashtag, \#YardFruits, was used to start the thread and make it searchable within Twitter for later reference. For the first nine threads, one species was discussed per thread. These species were, in order of posting, kumquat (Fortunella sp.), loquat (Eriobotrya japonica), blueberry (Vaccinium sp.), blackberry ( $R$ ubus subgenus $R u$ bus), grape (Vitis sp.), muscadine (Vitis rotundifolia), passion fruit (Passiflora sp.), fig (Ficus carica), and pear (Pyrus communis). The final thread consisted of single tweets of the following species: mayhaw ( $\mathrm{Cra}$ taegus sp.), pineapple guava (Feijoa sellowiana), false strawberry (Potentilla indica), pomegranate (Punica granatum), southern dewberry $(R u$ bus trivialis), fuzzy raspberry (Rubus moluccanus var. trilobus), poison ivy with Virginia creeper (Toxicodendron radicans, Parthenocissus quinquefolia), and pawpaw (Asimina triloba). The final tweet had a Twitter-generated poll to obtain feedback on the entire thread series by asking if the user gained knowledge from the series (yes or no). Final metrics were taken $\mathrm{l}$ week after the last thread posted, which included impressions (number of times a tweet shows up in a user's timeline) and engagements (total number of times a user actively interacted with a tweet, including clicks, retweets, likes, replies, follows, and all other possible activity). Engagement rate is defined as the number of engagements divided by impressions.

Data were obtained from Twitter Analytics (Twitter, Inc.). Analysis was performed in JMP (version 12; SAS Institute, Cary, NC) with the Fit model procedure and means were separated by Tukey's honestly significant difference test at $P \leq 0.05$.

\section{Results and discussion}

The average Twitter user has $\approx 700$ followers (Iqbal, 2020), but 
Table 1. Twitter metrics for \#YardFruits tweet thread of fruit crops from 6 Apr. to 8 June 2020.

\begin{tabular}{|c|c|c|c|c|c|c|}
\hline $\begin{array}{l}\text { Date of } \\
\text { posting }\end{array}$ & Fruit crop & $\begin{array}{c}\text { Total impressions }^{\mathrm{z}} \\
\text { (no.) }\end{array}$ & $\begin{array}{c}\text { Total engagements } \\
\text { (no.) }\end{array}$ & $\begin{array}{c}\text { Mean engagement } \\
(\%)\end{array}$ & $\begin{array}{c}\text { Total likes } \\
\text { (no.) }\end{array}$ & $\begin{array}{c}\text { Total retweets } \\
\text { (no.) }\end{array}$ \\
\hline 6 Apr. & Kumquat & 13,114 & 988 & $5.3 \mathrm{ab}^{\mathrm{w}}$ & 136 & 26 \\
\hline 20 Apr. & Blackberry & 11,253 & 720 & $4.4 \mathrm{ab}$ & 118 & 20 \\
\hline 27 Apr. & Blueberry & 11,959 & 652 & $4.3 \mathrm{ab}$ & 122 & 32 \\
\hline 4 May & Grape & 7,467 & 432 & $4.1 \mathrm{~b}$ & 60 & 23 \\
\hline 25 May & Fig & 6,867 & 431 & $3.5 \mathrm{~b}$ & 54 & 12 \\
\hline 1 June & Pear & 3,860 & 206 & $3.1 \mathrm{~b}$ & 27 & 8 \\
\hline \multirow[t]{3}{*}{8 June } & Other & 4,580 & 358 & $7.5 \mathrm{a}$ & 47 & 11 \\
\hline & Total/Avg & 80,438 & 5,280 & 4.5 & 799 & 182 \\
\hline & $P$ value & - & - & 0.003 & - & - \\
\hline
\end{tabular}

${ }^{\mathrm{z}}$ The number of times a tweet shows up in a user's timeline.

y The total number of times a user actively interacted with a tweet, including clicks, retweets, likes, replies, follows, and all other possible activity.

${ }^{\mathrm{x}}$ The number of engagements divided by impressions.

${ }^{w}$ Means followed by the same letter within the column were not deemed to be significantly different by Tukey's honestly significant difference at $P \leq 0.05$.

there is no accepted standard minimum number of followers for a successful account. Interest measured via engagement and steady follower growth would be aspirational targets. With those objectives in mind, my Twitter account saw a $6.5 \%$ increase in followers $(+137)$ from April through June, growing from 1980 to 2117 . My account grew by using welltargeted, focused tweets and tweet threads, especially those that used hashtags and photos (Barton et al., 2017; Seger et al., 2017). Hutto et al. (2013) found that key methods to attract followers included sharing informative content, encouraging discussion, and providing feedback. The 3 months before the \#YardFruits tweets (January, February, and March) averaged $\approx 46,500$ impressions, 17 new followers, and 269 profile visits; whereas April, May, and June averaged 121,000 impressions, 47 new followers, and 897 profile visits. This trend continued into July, after the thread series was over, with 118,000 impressions, 36 new followers, and 1048 profile visits, suggesting the sustained gains were likely a result of the tweet thread series.

Engagement percentage did not differ over time but did differ among the crop species (Table 1). The tweet thread from 8 June listed several different species vs. having only one in the other threads and had the highest engagement percentage $(7.5 \%)$, possibly due to the broader appeal for my diverse follower audience. Grape, passionfruit, fig, and pear threads had the least engagement and were different from the Other Fruits thread. Kumquat, loquat, blueberry, blackberry, and muscadine were similar to the rest. The engagement percentage shows that tweet threads were primarily viewed as one-way communication (Chung, 2017; Su et al., 2017).

Tweets absent a photo (10) received less engagement $(2.7 \%)$ than those that included a photo [90 $(4.7 \%)]$, consistent with other reports (Barton et al., 2017; Chung, 2017; Zhang et al., 2020) that show visual content can improve engagement. However, Han et al. (2019) found that audience preference may also play a role in desire for photos, videos, and hashtags. A few of the non-photo tweets $(\mathrm{n}=6)$ included a GIF meme, used as a humorous placeholder when a specific photo was not available. With such a small sample size it was impossible to determine if they were as effective as a photo; however, the data available suggest an actual photo was preferred.

Mean number of likes declined over time $(P=0.01)$, whereas number of impressions, engagements, and retweets were not significantly different (data not shown). Reasons for this decline could potentially be explained by several factors, including warming weather leading to less computer time, overall COVID-19 news fatigue, and competing news that dominated feeds (e.g., riots, racial inequality).

Most previous studies focused on analyzing data across multiple Twitter users and not a single user with a specific, directed educational content thread, as this study did. As with most extension programs, the goal is transformative life and knowledge changes. Interactions with other Twitter followers and happenstance viewers were positive and they often replied to the tweet thread with questions or comments related to the content. The poll at the end of the final tweet thread had a $100 \%$ positive response that something was learned from the series, but there were only 22 respondents.

Growing a Twitter following is work and requires significant time to generate engaging content. However, a researcher or extension worker who wishes to grow their follower number could use the method presented here to do so. Social media has the benefit of quantitative data and thus can be reported as part of jobduty requirements (Gharis and Hightower, 2017). As universities continue to explore and encourage the integration of online learning environments, effective use of Twitter and other platforms will become normative, rather than explorative, activities.

\section{Literature cited}

Barton, E., E. Barton, S. Barton, C. Boyer, J. Brosnan, P. Hill, J. Hoyle, J. Reid, J. Seger, and E.T. Stafne. 2017. Using technology to enhance extension education and outreach. Hort Technology 27:177-186, doi: 10.21273/HORTTECH03608-16.

Chung, J.E. 2017. Retweeting in health promotion: Analysis of tweets about breast cancer awareness month. Comput. 
Human Behav. 74:112-119, doi: 10.1016/ j.chb.2017.04.025.

Gharis, L.W. and M.F. Hightower. 2017. A practical method for collecting social media campaign metrics. J. Ext 55(2):2IAW6. 15 Sept. 2020.<https://www.joe.org/joe/ 2017april/iw6.php>.

Han, X., G. Xingyu, and S. Peng. 2019. Analysis of tweet form's effect on users' engagement on Twitter. Cogent Business Mgt. 6:1-15, doi: 10.1080/23311975. 2018.1564168 .

Hoke, A.M., E.B. Francis, E.A. Hivner, A.J. Lipsett Simpson, R.E. Hogentogler, and J.L. Kraschnewsk. 2018. Investigating the effectiveness of webinars in the adoption of proven school wellness strategies. Health Educ. J. 77:249-257, doi: $10.1177 / 0017896917734017$.

Hummer, K. 2020. COVID-19 and horticulture: Personal views. Chronica Hort. 60(2):8-11.

Hutto, C.J., S. Yardi, and E. Gilbert. 2013. A longitudinal study of follow predictors on Twitter. Proc. SIGCHI Conf. Human Factors Comput. Syst. Apr.:821-830. https://doi.org/10. $1145 / 2470654.2470771$.

Iqbal, M. 2020. Twitter revenue and usage statistics. 15 Sept. 2020. <https:// www.businessofapps.com/data/twitterstatistics $/>$.
Mills, J., M. Reed, K. Skaalsveen, and J. Ingram. 2019. The use of Twitter for knowledge exchange on sustainable soil management. Soil Use Mgt. 35:195-203, doi: 10.1111 /sum.12485.

Particka, C.A., E.T. Stafne, and T.E. Martinson. 2018. Assessment and valuation of the Northern Grapes Project webinar series. HortTechnology 28:524-528, doi: 10.21273/HORTTECH04088-18.

Ruth, T.K., T. Suits, A. McLeod-Morin, and R.W. Telg. 2020. Utilizing Twitter to communicate risk after a natural disaster. J. Appl. Commun. 104(1), doi: 10.4148/ 1051-0834.2301.

Seger, J., P. Hill, E.T. Stafne, and E. Swadley. 2017. Twitter chats: Engaging niche audiences where they are. J. Ext. 55(2):2TOT3. 15 Sept. 2020. <https:// www.joe.org/joe/2017april/tt3.php>.

Stafne, E.T. 2020. Mississippi fruit and nut blog. 15 Sept. 2020. <https:// msfruitextension.wordpress.com $/>$.
Su, L.Y.-F., D.A. Scheufele, L. Bell, D. Brossard, and M.A. Xenos. 2017. Information-sharing and community-building: Exploring the use of twitter in science public relations. Sci. Commun. 39:569597, doi: 10.1177/1075547017734226.

Wagler, A. and K. Cannon. 2015. Exploring ways social media data inform public issues communication: An analysis of Twitter conversation during the 20122013 drought in Nebraska. J. Appl. Commun. 99:44-60, doi: 10.4148/10510834.1047 .

Zhang, S., J.F. Gosselt, and M.D.T. de Jong. 2020. How large information technology companies use Twitter: Arrangement of corporate accounts and characteristics of tweets. J. Bus. Tech. Commun. 34:364-392, doi: 10.1177/ 1050651920932191. 
Dr. Stafne @EStafne·Apr 6, 2020

Replying to @EStafne

The trees are self-fertile, so a single tree can produce fruit. Fruit shape ranges from oblong to round depending on variety. Fruit is entirely edible, including rind. However, they have seeds and are not very juicy. Typically, the outer rind is sour but the inner pulp is sweet.

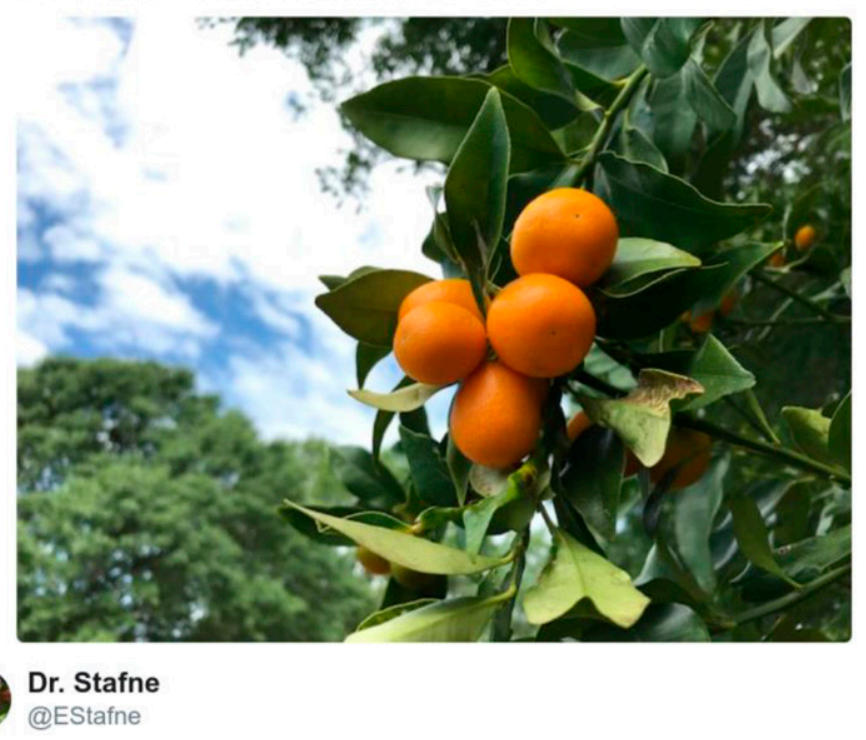

In my yard, I have a variety called 'Nagami' that has mostly oblong fruit. They usually contain 2-5 seeds. Here in south Mississippi they begin to ripen in winter and continue into spring. It can produce prodigious crops of hundreds of fruits per year.

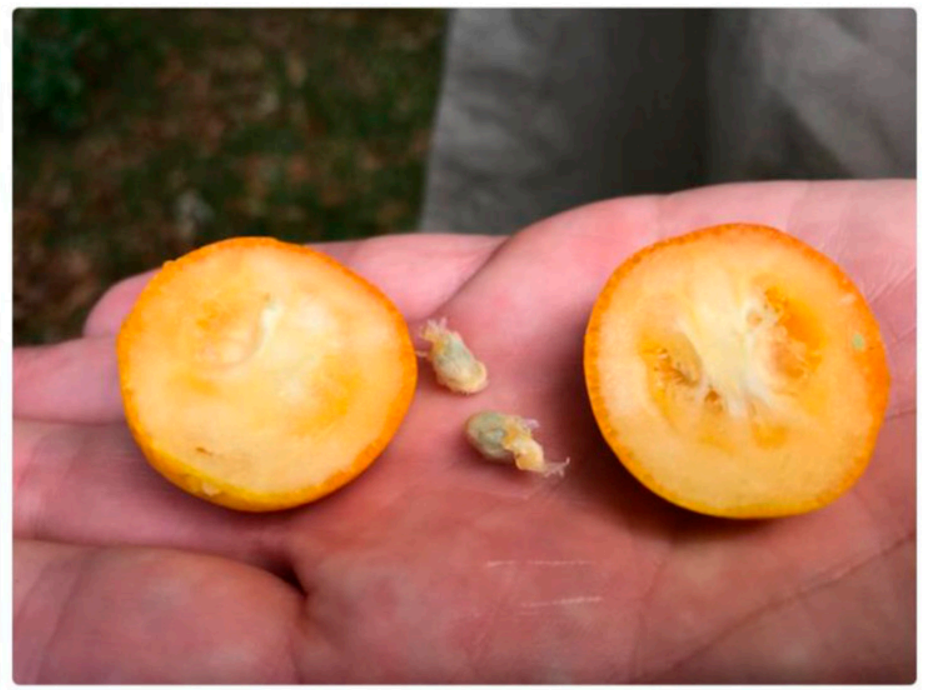

O 5 4:43 PM - Apr 6, 2020

\& See Dr. Stafne's other Tweets

Supplemental Fig. 1. Representative tweets within the kumquat thread from 6 Apr. 2020. 